\section{The effect of fish-oil on the remission of Type 1 (insulin-dependent) diabetes in newly diagnosed patients}

\section{Dear Sir,}

Type 1 (insulin-dependent) diabetes is thought to be the result of a chronic autoimmune process $[1,2]$ which eventually leads to B-cell destruction. The onset of the disease is followed in about $11 \%$ of patients by a transitory remission phase, which may be related to preservation of residual insulin secretory capacity [3]. A diet rich in fish oil has antiinflammatory properties as indicated by the suppression of autoimmunity in MRL-lpr mice [4]. It is thus possible that a diet rich in eicosapentaenoic acid (EPA) could modulate the immune response and prevent further B-cell damage in newly-diagnosed Type 1 diabetes mellitus.

In a pilot study, we have investigated the effect of dietary supplementation with fish-oil on remission of newly-diagnosed Type 1 diabetes mellitus. Remission was defined as a blood glucose value less than $7.8 \mathrm{mmol} / 1$ fasting and $11.1 \mathrm{mmol} / \mathrm{l}$ post-prandially $(2 \mathrm{~h}$ after breakfast), and a normal $\mathrm{HbA}_{1}(4.9-7.5 \%)$ level in the absence of insulin treatment.

Eight ( 5 male, 3 female) newly-diagnosed ketosis prone Type 1 diabetic patients, aged between 14 and 38 years (mean 25 years), were recruited within 2 weeks of the onset of diabetes. Following baseline assessment, patients were randomly assigned to a standard diabetic diet supplemented either with $20 \mathrm{~g}$ MaxEPA (Markfleet Refining Company, Hull, UK) daily, in the form of $20 \mathrm{ml}$ oil, equivalent to $3.6 \mathrm{~g}$ EPA, $2.4 \mathrm{~g}$ docosahexaenoic acid and $180 \mathrm{kcal}$ (4 patients) or with an isocaloric amount of olive oil ( 4 patients). All patients were treated with a mixture of soluble and intermediate acting insulins twice daily. Further assessments were made at 1 month and then every 3 months up to 9 months. Diabetic control was assessed by home blood glucose profile and $\mathrm{HbA}_{1}$ levels. Dietary compliance was checked by a dietician at each visit. Heparinised blood was taken for isolation of monocytes, lymphocytes and neutrophils as previously described [5]. Lymphocytes were used for measurement of HLA-DR, interleukin 2 (IL-2), islet cell antibodies (ICA) and complement-fixing islet cell antibodies (CF-ICA). Monocytes and neutrophils were used for analysis of membrane phospholipids [5].

Diabetic control improved similarly in both groups after the initiation of therapy, but it was not possible to withdraw insulin in any patient (Table 1). Cholesterol levels fell by $5 \%$ and triglyceride by $22 \%$ approximately in the experimental group with similar changes were seen in the control group. Platelet counts decreased in the experimental group only by $15 \%$ over the course of the study.

Membrane phospholipid analysis of monocytes and neutrophils showed an approximately ten-fold increase in EPA from $0.35 \%$ total

Table 1. Mean \pm SEM blood glucose, $\mathrm{HbA}_{1}$, and daily insulin dose in 8 Type 1 (insulin-dependent) diabetic patients receiving a diet supplemented with either fish or olive oil

\begin{tabular}{|c|c|c|c|c|c|c|}
\hline & \multicolumn{2}{|c|}{$\begin{array}{l}\text { Mean blood glucose } \\
(\mathrm{mmol} / \mathrm{l})\end{array}$} & \multicolumn{2}{|l|}{$\mathrm{HbA}_{1} \%$} & \multicolumn{2}{|c|}{ Insulin (U/day) } \\
\hline & Fish oil & Olive oil & Fish oil & Olive oil & Fish oil & Olive oil \\
\hline Baseline & $7.9 \pm 0.9$ & $6.7 \pm 0.7$ & $9.8 \pm 1.2$ & $10.2 \pm 0.8$ & $30 \pm 6.0$ & $39 \pm 4.7$ \\
\hline 1 month & $7.2 \pm 1.2$ & $6.3 \pm 1.1$ & $8.3 \pm 0.6$ & $7.9 \pm 0.2$ & $30 \pm 10.2$ & $37 \pm 5.7$ \\
\hline 3 months & $7.3 \pm 2.0$ & $6.1 \pm 0.7$ & $7.9 \pm 1.0$ & $7.0 \pm 0.6$ & $27 \pm 9.4$ & $37 \pm 5.8$ \\
\hline 6 months & $9.9 \pm 2.4$ & $5.6 \pm 0.6$ & $8.8 \pm 1.5$ & $6.4 \pm 0.4$ & $36 \pm 13.3$ & $36 \pm 8.3$ \\
\hline 9 months & $7.4 \pm 2.9$ & $6.5 \pm 0.9$ & $7.7 \pm 0.8$ & $7.0 \pm 0.7$ & $38 \pm 14.4$ & $39 \pm 8.1$ \\
\hline
\end{tabular}

fatty acid content to $3.73 \%$, and a decrease in arachidonic acid content from $15.95 \%$ to $12.68 \%$ in the experimental group confirming incorporation and compliance. The control group showed approximately a $78 \%$ increase in EPA, with approximately a $10 \%$ decrease in arachidonic acid.

At diagnosis 5 patients ( 2 experimental, 3 control) were ICA positive and 4 patients ( 3 experimental, 1 control) were CF-ICA positive. By the end of the study 3 patients remained ICA positive (1 experimental, 3 control) and 2 remained ICA positive (1 experimental, 1 control). HLA-DR and IL-2 showed no consistent changes during treatment in either group.

Short-term dietary supplementation with MaxEPA has been reported to induce either a deterioration or no change in glycaemic control and insulin requirement in Type 1 diabetic patients of some duration $[6,7]$. A hypercholesterolaemic effect has been noted by some authors [7]. In Type 2 (non-insulin-dependent) diabetic patients MaxEPA has been shown to improve insulin sensitivity by some workers [8] but other authots have found a worsening of metabolic control $[6,9]$. The findings of the present study suggest that long-term supplementation of a diabetic diet with MaxEPA does not affect the autoimmune process of newly-diagnosed Type 1 diabetes mellitus.

Yours sincerely,

T. Tariq, C. Close, R. Dodds, G.C. Viberti, T. Lee and D. Vergani

\section{References}

1. Eisenbarth GS (1986) Type 1 diabetes: a chronic autoimmune disease. N Engl J Med 314: 1360-1368

2. Nerup J, Lernmark $\AA$ (1981) Autoimmunity in insulin-dependent diabetes mellitus. Am J Med 70: 135-141

3. Madsbad S (1983) Prevalence of residual B cell function and its metabolic consequences in Type 1 (insulin-dependent) diabetes. Diabetologia 24: 141-147

4. Kelley VE, Ferretti A, Izui S, Stram TB (1985) A fish oil diet rich in eicosapentaenoic acid reduces cycloxygenase metabolites and suppresses lupus in MRL-1 pr mice. J Immunol 134: 1914-1919

5. Lee TH, Hoover RL, Williams JD, Sperling RJ, Ravalese J III, Spur BW, Robinson DR, Corey EJ, Lewis RA, Austen KF (1985) Effect of dietary enrichment with eicosapentaenoic and docosahexaenoic acids in vitro neutrophil and monocyte leukotriene generation and neutrophil function. N Engl J Med 312: 1217-1224

6. Horwitz N (1987) Fish oil decontrols diabetes. Medical Tribune, Wednesday July 8 , pp 1

7. Vandongen $R$, Mori TA, Codde JP, Stanton KG, Masarei JRL (1988) Hypercholesterolaemic effect of fish oil in insulin-dependent diabetic patients. Med J Aust 148: 141-143

8. Popp-Snijders C, Schouten JA, Heine RJ, Van Der Meer J, Van Der Veen EA (1987) Dietary supplementation of omega-3 polyunsaturated fatty acids improves insulin sensitivity in non-insulin-dependent diabetes. Diabetes Res 4: 141-147

9. Glauber J, Wallace P, Griver K, Brechtel G (1988) Adverse metabolic effect of omega-3-fatty acids in non-insulin-dependent diabetes mellitus. Ann Intern Med 108: 663-668

Prof. G.C. Viberti

Unit for Metabolic Medicine

4th Floor Hunts House

UMDS - Guy's Hospital

London SE1 9RT

UK 